\title{
Measuring Soil Surface Roughness with the RealSense D435i
}

\author{
Moisei Trosin ${ }^{1}$, Igor Dekemati ${ }^{2}$, István Szabó ${ }^{3}$ \\ ${ }^{1}$ Doctoral School of Mechanical Engineering, Hungarian University of Agriculture \\ and Life Sciences, Páter Károly utca 1, 2100 Gödöllő, Hungary, \\ trosin.moisei@hallgato.uni-mate.hu \\ ${ }^{2}$ Department of Agronomy, Institute of Crop Production Sciences, Hungarian \\ University of Agriculture and Life Sciences, Páter Károly utca 1, 2100 Gödöllö, \\ Hungary, dekemati.igor@uni-mate.hu \\ ${ }^{3}$ Department of Machine Construction, Institute of Technology, Hungarian \\ University of Agriculture and Life Sciences, Páter Károly utca 1, 2100 Gödöllö, \\ Hungary, szabo.istvan.prof@uni-mate.hu
}

\begin{abstract}
We present a novel application of the D435i, an RGBD camera, designed by Intel. The device can be used by soil scientists, as a low-cost, high-resolution, short-range $3 D / 4 D$ camera imaging system, producing data similar to a terrestrial light detection and ranging (LiDAR) sensor. The D435i contains a structured light emitter, two infrared cameras, a visible wavelength camera, an Inertial Measurement Units (IMU) combining accelerometer and gyroscope. The affordable camera has 90 frame rate, spatial and depth resolutions which are $\mathrm{mm}$ or $\mathrm{cm}$ depending on range, and the optimal operating range is 0.5 to $\sim 5 \mathrm{~m}$. We describe data collection and basic data analysis routines in an agricultural field, on the long-term experiment, designed to demonstrate the breadth and utility of this new sensor in soil roughness measurment.
\end{abstract}

Keywords: remote sensing; soil surface roughness; image processing

\section{Introduction}

Soil surface roughness (SSR) is defined as the average of vertical deviations from a nominal surface over a specified surface area, caused by factors such as soil texture, aggregate size, rock fragments, vegetation cover and land management, more precisely, soil tillage [1]. According to different order of magnitudes of roughness elements, SSR is classified by four main types [2]. Impact of tillage belongs to the third group at the scale of approximately 2-200 $\mathrm{mm}$, where differences is resulted of tillage impact. Consequently, in agricultural production, SSR is an essential component in preserving the soil moisture content whereby 
provided greater availability to plants and safety crop production [3]. Besides that, Li et al. [4] highlighted the importance the soil surface roughness in water erosion processes.

Since the first conducted experiments for SSR measurements, with invasive (contact methods), for example, a roller chain and pinboard, plenty of noninvasive methods, based on applying a variety of digital devices, have been developed [5]. Old and modern methods were compared [1] [6] where the distinct advantage of new non-contact methods was revealed.

However, the quick and affordable measurement technique of SSR is not yet appropriately solved. The modern approaches based on 3D scanning technologies and generating a digital elevation model (DEM) include laser scanning [7], synthetic aperture radar [8] [9], time-of-flight light detection and ranging (LiDAR), and photogrammetry. LIDAR and Terrestrial Laser Scanners (TLS) has good spatial accuracy, but still relatively expensive [1].

Photogrammetric methods might be classified by working principal into two groups as passive and active, where passive method has no outcome source of waves to project on object. The photogrammetry approach is usually represented by stereo camera devices, but some researchers use one digital camera and make a series of images with an angular displacement around the object.

The passive approach with one digital camera for measuring surface roughness $[10,11,12]$ requires a set of photos around the capturing place which takes a relatively long time. Mirzaei and Ruy [13] applied another method to obtain SSR with 2 digital cameras. A common disadvantage of passive methods is the difficulty in recognizing features to be matched with uniformly colored surfaces, like a white wall or black desk.

Active methods overcome this issue with an active texture projector, which creates a pattern of dots on the scanned objects. This technique was used by classical stereo systems [14].

From the time when cheap and feasible depth cameras came to the market, many research projects are implementing 3D scanning technologies for diverse areas including soil science. First generation, low cost RGB-D cameras, were used for glaciology, stream bathymetry and geomorphology [15], with Microsoft Kinect and SSR measuring [1] with ASUS Xtion.

Further development of RGB-D cameras improved accuracy, quality and provided higher depth resolution of 3D scans. Nowadays, many producers offer their RGB-D camera, the commonly used units are the RealSense D400 series from Intel, Azure Kinect and Kinect 2 from Microsoft and the ASUS Xtion2.

The focus of this paper is to provide a basic overview of the D435i, as a soil science research tool, by describing its specifications, limitations and example applications. We describe the hardware and software interface and discuss the 
quality of the data collected by the instrument and its accuracy without tuning parameters of camera or sophisticated post-processing. We then present the first published examples using the D435i in the soil science domain, demonstrating uses in measuring soil surface roughness.

\section{Methods and Materials}

\subsection{Hardware Specifications}

The RGB-D camera D435i (Fig. 1) detects the distance from itself to objects within its field of view (FOV), by emitting a random focused Infra-Red (IR) dot pattern with a projector and recording that pattern with right and left IR cameras. The depth is derived primarily by matching the simultaneously captured left and right video images, determining the disparity for each pixel (i.e. shift between object points in left vs right images) and calculating the depth map from this disparity and triangulation.

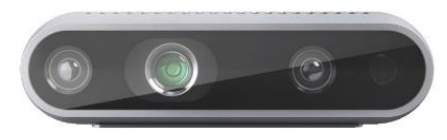

Figure 1

Camera D435i. Source: intelrealsense.com

The depth algorithm in the RealSense D4 Stereo-vision ASIC is able to recognize the slightest texture in a scene, especially in bright environments, and therefore, works extremely well outdoors.

The pattern changes with distance (Fig. 2), expanding radially from the IR emitter point source until it is displayed upon the surface of interest.

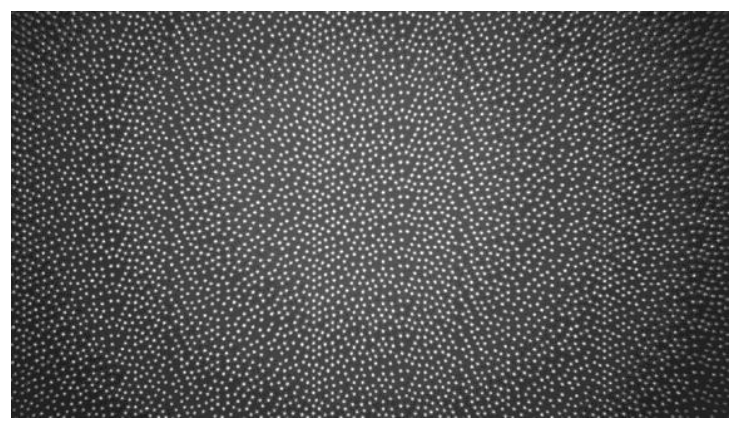

Figure 2

The infrared (IR) pattern projected by the IR emitter. Source: dev.intelrealsense.com 
The device has a quite compact profile and is light weight (dimensions: $90 \mathrm{~mm} \mathrm{x}$ $25 \mathrm{~mm}$ x $25 \mathrm{~mm}$, weight: $258 \mathrm{~g}$ ), passively cooled, can either be integrated with a computer and/or a mobile device or used as an independent device. The processor, the Intel RealSense Vision Processor D4 Board, performs depth stereo vision processing and communicates with the host processor through USB-C2.0 / USB 3.1 Gen 1.

The D435i is equipped with a color camera and provides texture information to be superimposed on the depth data (Table 1).

Table 1

Technical specification d435i

\begin{tabular}{|l|l|l|}
\hline Parameters & Properties & Units \\
\hline Depth Field of View (FOV) & $87 \pm 3 \times 58 \pm 1 \times 95 \pm 3$ & $\left(^{\circ}\right)$ \\
\hline IR camera resolution & $1280 \times 720$ & $(\mathrm{pix})$ \\
\hline Depth Frame Rate & 30 & $(\mathrm{~Hz})$ \\
\hline RGB camera resolution & $1920 \times 1080$ & $(\mathrm{pix})$ \\
\hline Maximum frame rate & 90 & $(\mathrm{~Hz})$ \\
\hline Baseline & 50 & $(\mathrm{~mm})$ \\
\hline Measurement range & $200-10000$ & $(\mathrm{~mm})$ \\
\hline
\end{tabular}

The camera is factory-calibrated, and the intrinsic and extrinsic parameters of the sensors are stored on board and easily accessible via the Librealsense APIs. In addition, a variety of third-party methods for calibration exist [16] [17].

The following equation represents the theoretical limitation for the RMS depth error (Fig. 3). The RMS error represents the depth noise for a localized plane fit to the depth values:

$$
\begin{gathered}
\text { Depth RMS error }(\mathrm{mm})=\frac{\text { Distance }(\mathrm{mm})^{2} * \text { Subpixel }}{\text { focal length }(\text { pixels }) * \text { Baseline }(\mathrm{mm})} \\
\text { where focal length }(\text { pixels })=\frac{1}{2} \frac{\operatorname{Xres}(\text { pixels })}{\tan \left(\frac{H F O V}{2}\right)}
\end{gathered}
$$

Where: Subpixel $=0.08$

$$
\begin{aligned}
& \text { Xres }=848 \\
& \text { HFOV }=90 \mathrm{deg}
\end{aligned}
$$

The D435i can detect surfaces at distances to $10 \mathrm{~m}$, but errors are large at that range, so we only show data to a maximum of $5 \mathrm{~m}$. Although the minimum resolution (minimum step size) presented here is $1 \mathrm{~mm}$. Therefore, the resolution of the sensor is better than $1 \mathrm{~mm}$ at close range. 


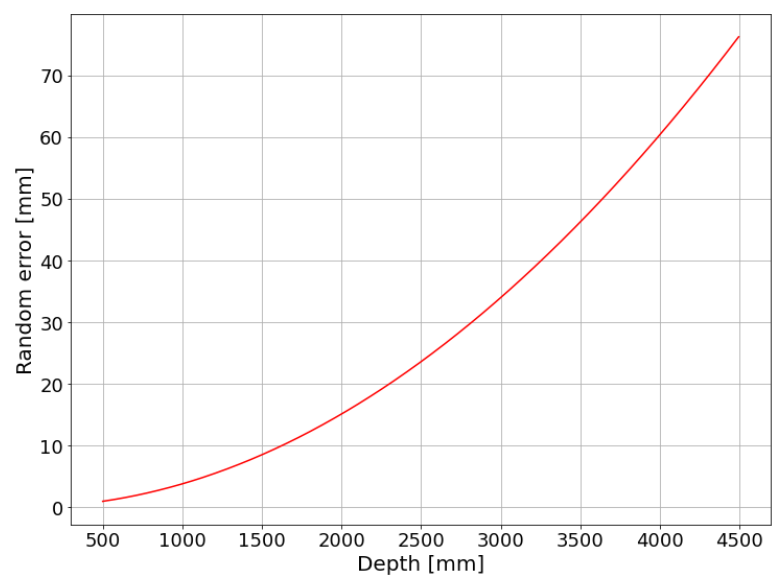

Figure 3

Theoretical random error with depth along $\mathrm{Z}$ (unity disparity error)

\subsection{D-Images Acquisition}

The study site (Fig. 4) is located at the Training Farm (JETF) of Szent István University ( $47^{\circ} 41^{\prime} 30.6^{\prime \prime}$ latitude N, - 19 $36^{\prime} 46.1^{\prime \prime}$ longitude E; $110 \mathrm{~m}$ above sea level), North-East from Budapest, established in 2002 [18] [19].

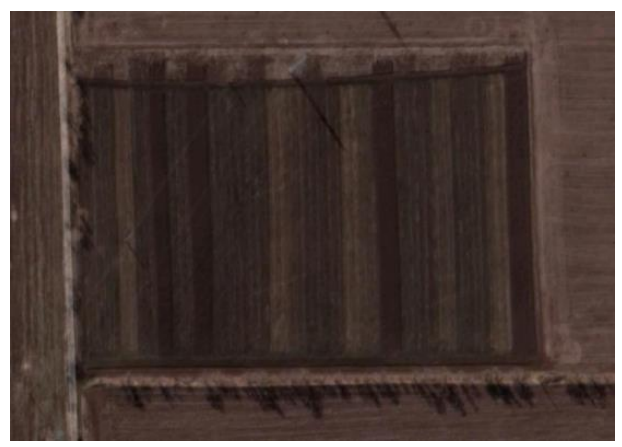

Figure 4

The long-term experiment at Józsefmajor Experimental and Training Farm. Source: google.com/maps

According to the World Reference Base Classification system, the soil is Endocalcic Chernozems (Loamic) with a clay loam texture [20]. Our experiment (Fig. 5) was arranged in a frame with $60 \mathrm{~cm} \times 50 \mathrm{~cm}$ sides and the camera was set up at the height of $60 \mathrm{~cm}$. Images were processed by laptop Dell 7577 in real-time. The outdoor part of experiment was carried out on October 3, 2019, at $3 \mathrm{pm}$, with partly cloudy sky, $+15^{\circ} \mathrm{C}$. 


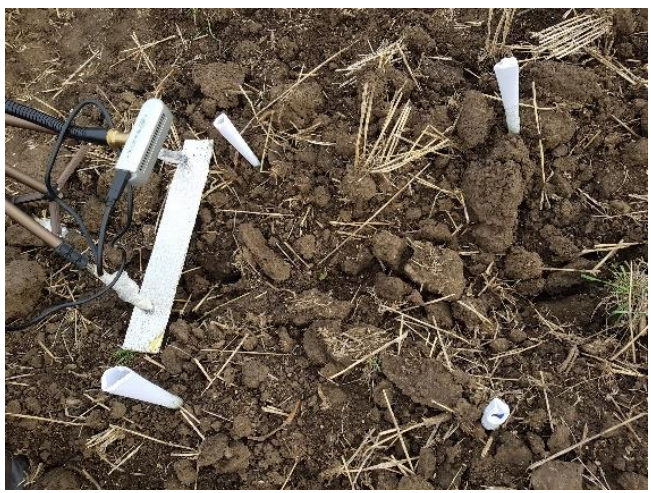

Figure 5

Experiment process

The experimental field of soil was prepared by a John Deere 7820 tractor (Fig. 6) with soil tillage equipment installed (Table 2).

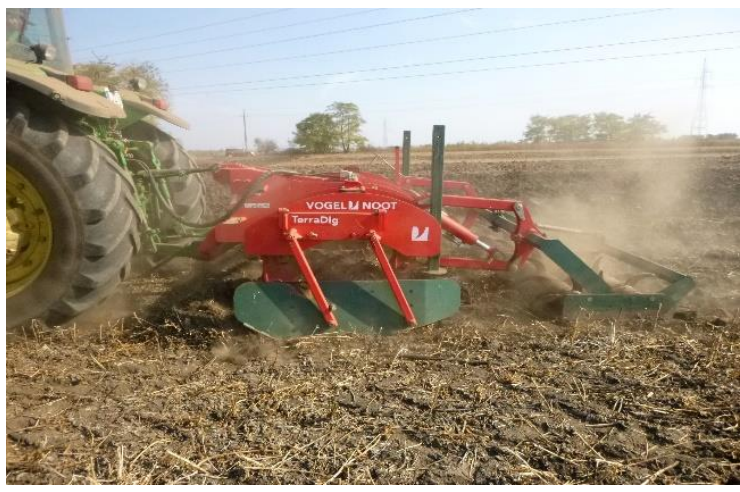

Figure 6

John Deere 7820 and Vogel\&Noot TerraDig XS subsoiler

Table 2

List of tillage treatments, applied equipment and working depth

\begin{tabular}{|l|l|l|}
\hline Tillage treatments & Equipment & $\begin{array}{l}\text { Working depth } \\
(\mathrm{cm})\end{array}$ \\
\hline Loosening (L) & Vogel \& Noot TerraDig XS & $40-45$ \\
\hline $\begin{array}{l}\text { Moldboard ploughing + levelling } \\
(\mathrm{P})\end{array}$ & Kverneland LM100 + packomat & $28-30$ \\
\hline Deep tine cultivation (DC) & Kverneland CLC Pro & $22-25$ \\
\hline Shallow tine cultivation (SC) & Kverneland CLC Pro & $18-20$ \\
\hline Disking (D) & Väderstad Carrier 500 & $12-14$ \\
\hline No-till & $\begin{array}{l}\text { Väderstad Rapid 300 C or Kuhn } \\
\text { Maxima 6 }\end{array}$ & $3-5$ (rows) \\
\hline
\end{tabular}


Digital images of soil roughness were captured from 6 parts of the field, with different tillage techniques, 2 samples per type of tillage treatment method.

The triangular irregular network (TIN) method uses a cloud of points to create continuous surfaces consisting entirely of triangular facets (Fig. 7). The resulting 3D images were saved to the Polygon File Format (.ply).

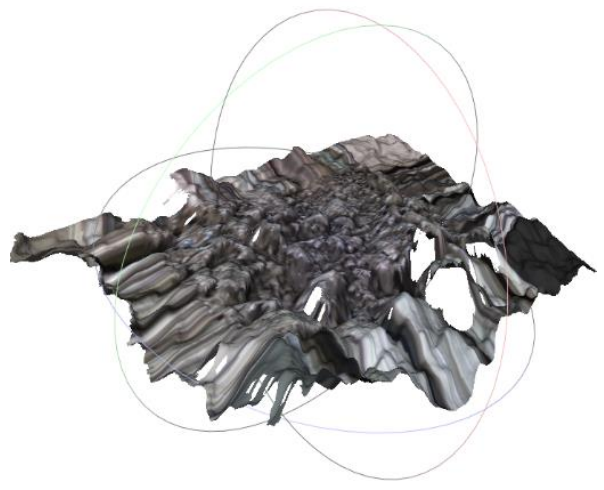

3D image of soil

\subsection{Accuracy Assessment Performed on Artificial Surfaces}

In order to determine the accuracy of the method applied to the soil surface measurement, several hemispheres with known sizes were 3D printed and arranged at measured positions (Fig. 8). This model aimed to simulate the soil surface structure.

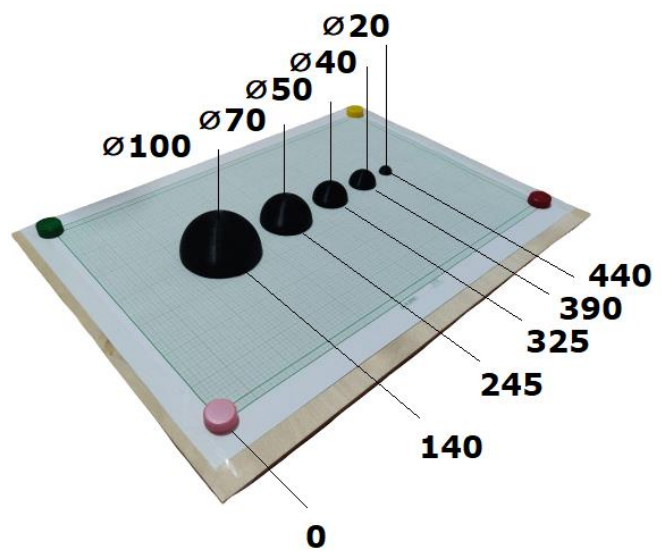

Figure 8

Artificial surface model built with 3D printed hemispheres 
Positional accuracies were estimated by comparing the real values to those calculated from our 3D images (Fig. 9).

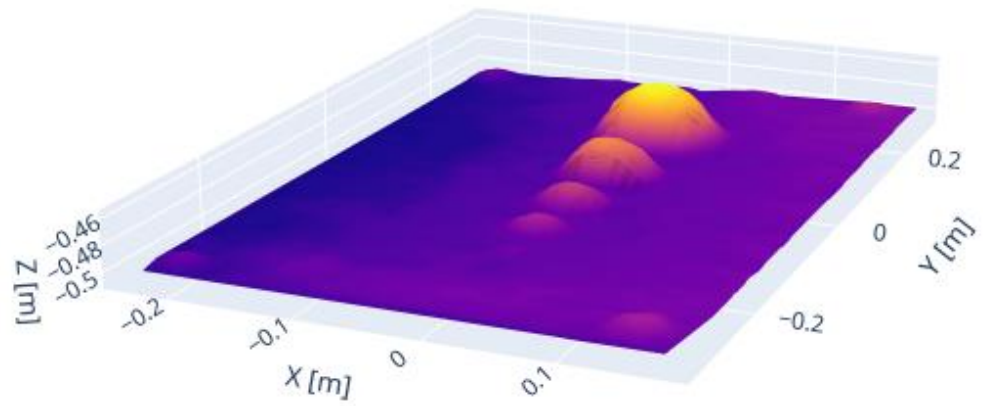

Figure 9

Plotted scan of hemispheres

Two types of errors were measured in this study:

- Linear error is a deviation of location hemisphere along the central line

- Radial error is a deviation of scanned points and surfaces of hemispheres

In order to obtain the central points of the hemispheres we used the Iterative Cloud Point (ICP) algorithm to fit spheres in the point cloud and to get the centers.

Linear error was calculated as distance from the reference point of the selected stand (zero point) and distances between each central point of the hemispheres

$$
\text { Distance }=\sqrt{\left(x_{2}-x_{1}\right)^{2}+\left(y_{2}-y_{1}\right)^{2}+\left(z_{2}-z_{1}\right)^{2}}
$$

along the central line (Fig. 10). Scanned points that lie on hemispherical surfaces were selected.

where $\mathrm{x}_{1}, \mathrm{y}_{1}, \mathrm{z}_{1}$ and $\mathrm{x}_{2}, \mathrm{y}_{2}, \mathrm{z}_{2}$ coordinates of two points in three-dimensional space.

The distances between these points and their corresponding hemispheres were calculated using the Euclidean equation. These distances were then compared to the true radius values to calculate the radial error. 


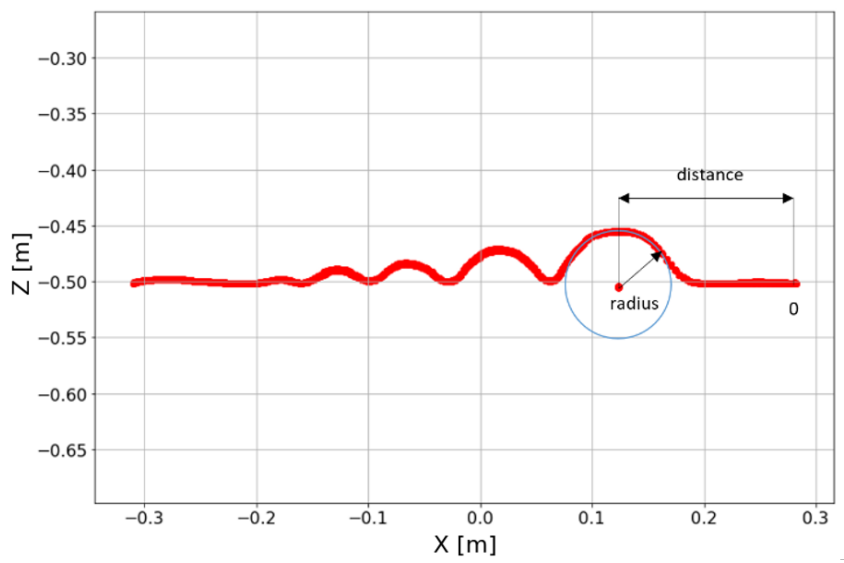

Figure 10

Profile of measured hemispheres

\subsection{The Complete Software Toolchain}

Intel provides a Software Development Kit (SDK) which supports the most popular programming languages such as Python, Java and $\mathrm{C}++$ and allows the design of concrete software for specific tasks. In our work several packages were used with Python 3.7 and Jupiter Notebook IDE, in the different processing stages:

- Data capture was accomplished by the designed software, using RealSense SDK and OpenCV libraries

- Numpy software processed the cloud points data: Reshaping, Values filtration and Calculating distances

- Data storage with Pandas

- Data represented with MPL toolkits, Matplotlib, Plotly

During the measurement process, in the field, all photographs were grouped and added to a database.

\section{Results and Discussions}

The camera was tuned with settings by default and mounted at a height of $0.5 \mathrm{~m}$ above the stand with hemispheres. Measurements were carried out in well-lit indoor environment. The acquisition is shown in Figure 11 with $100 \mathrm{~mm}$ hemisphere, as well as, a best fitting sphere. 


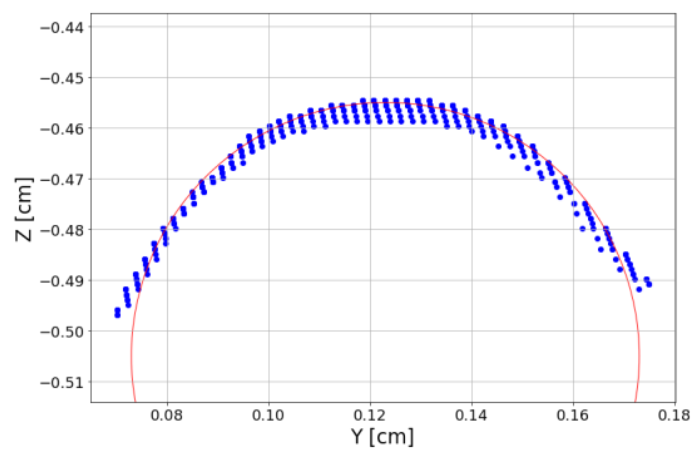

a)

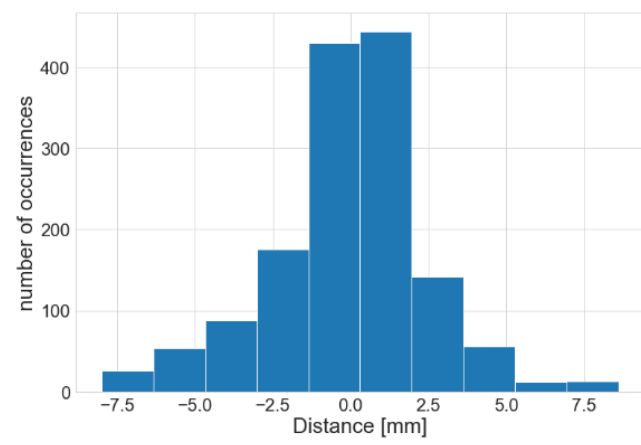

b)

Figure 11

Measuring of a $100 \mathrm{~mm}$ hemisphere. a) Profiles of scanned surface and fitted sphere. b) Histogram of measurement deviations in radiuses of scanned surface and fitted sphere

Figure 12 shows the result of measurements for the selected stand. The surface area of each sphere was measured and difference between fitted spheres and measurements obtained was calculated. The error distribution for $100 \mathrm{~mm}$ diameter is quite noticeable, but by implementing system adjustments, this can be reduced. We calculated the linear distances between central points of the spheres and compared them with the actual positions on the stand. We then fit a linear regression between them, with a coefficient of determination $\mathrm{R}^{2}=0.988$. 


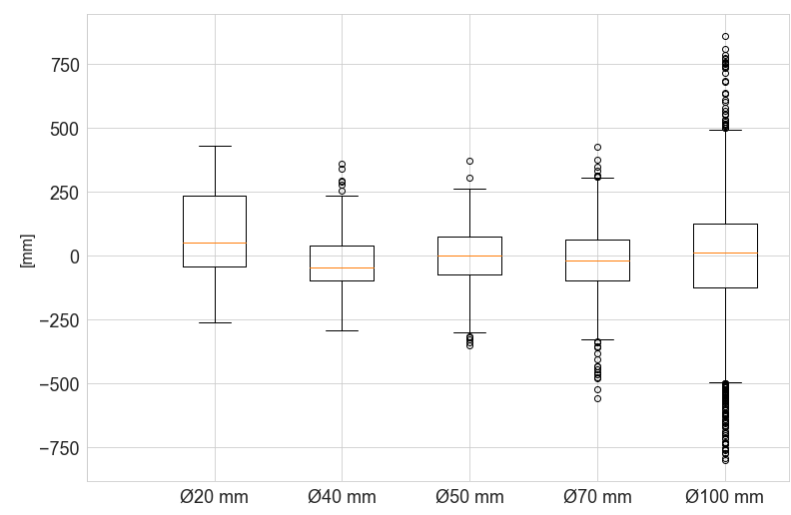

a)

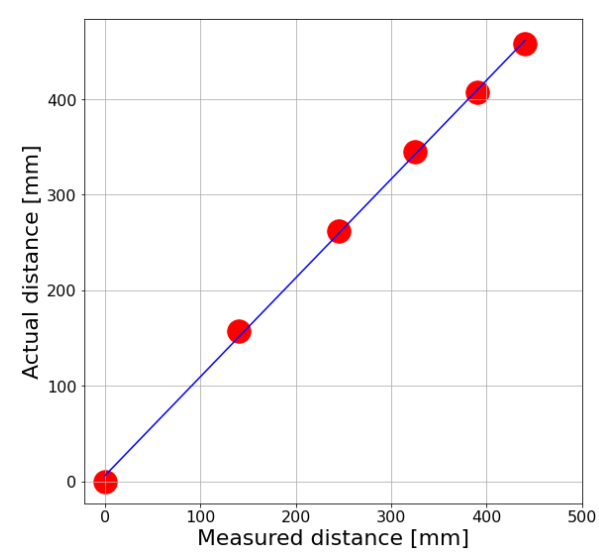

b)

Figure 12

Measurements of stand with hemispheres. a) Box plot of deviations of scanned surfaces from fitted spheres. b) Fitted regression between actual distances of hemispheres central points and measured ones

The system was applied for the data collection, with processing, for 6 different soil treatment methods (Fig. 13). 
No-till

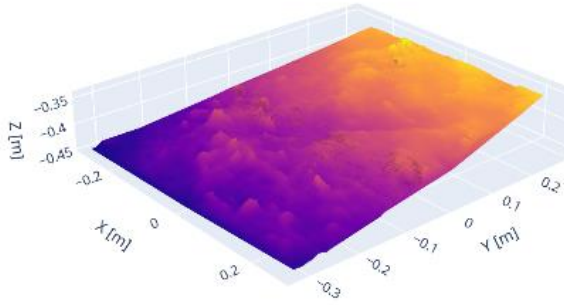

Deep tine cultivation

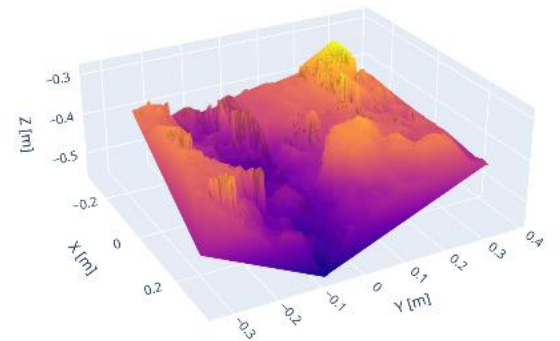

Shallow tine cultivation

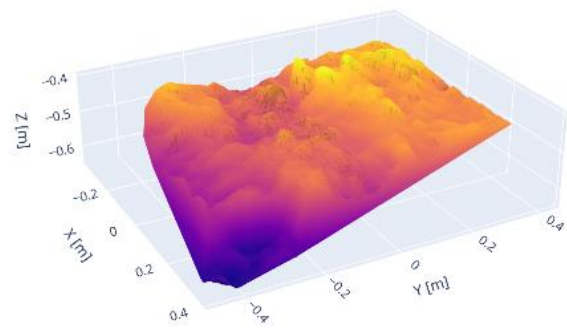

Disking

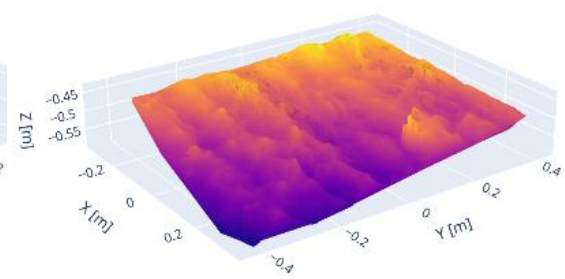

Ploughing

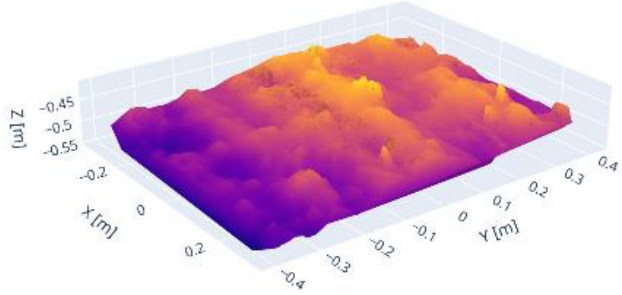

Subsoiling

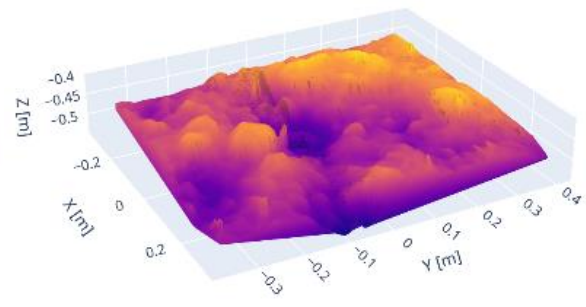

Figure 13

Obtained 3D samples of soil

Figure 14 presents profiles of each soil plot, with specific geometric features depending on tillage treatments.
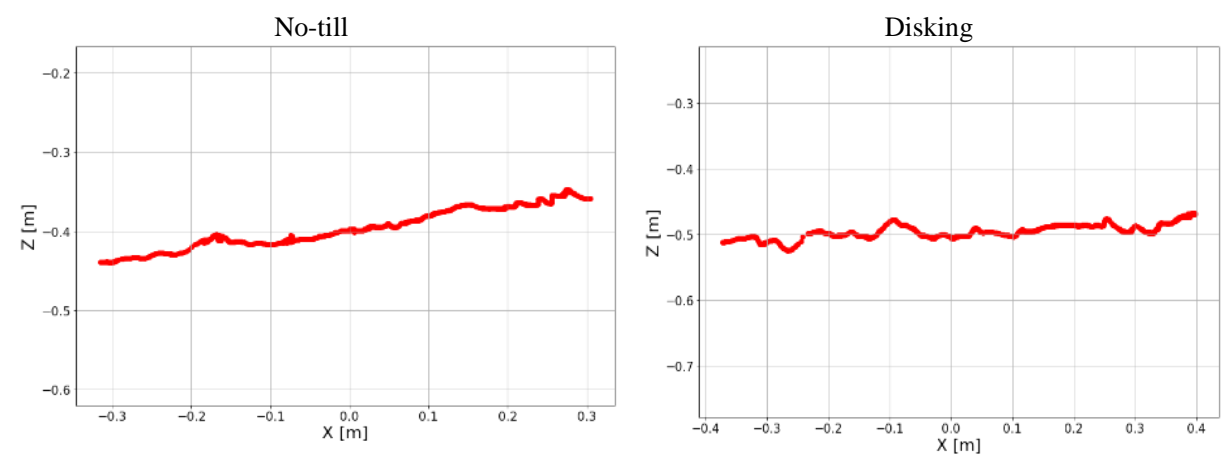


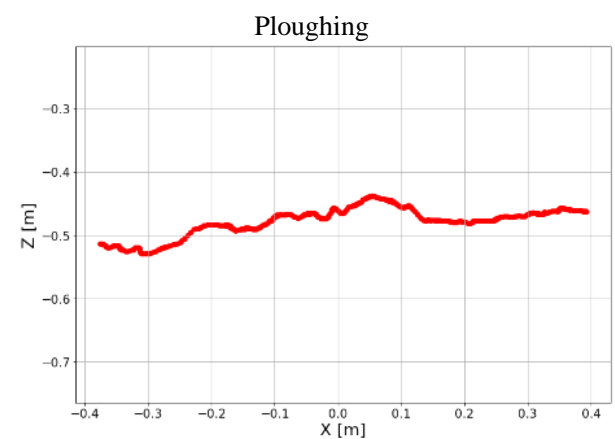

Deep tine cultivation

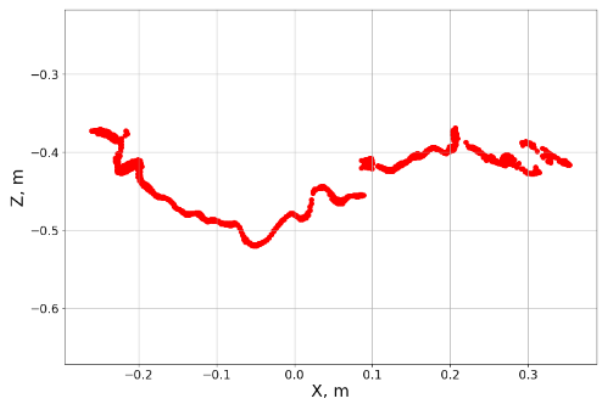

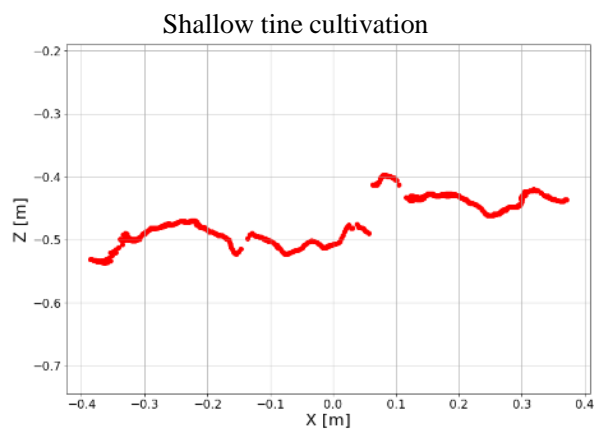

Subsoiling

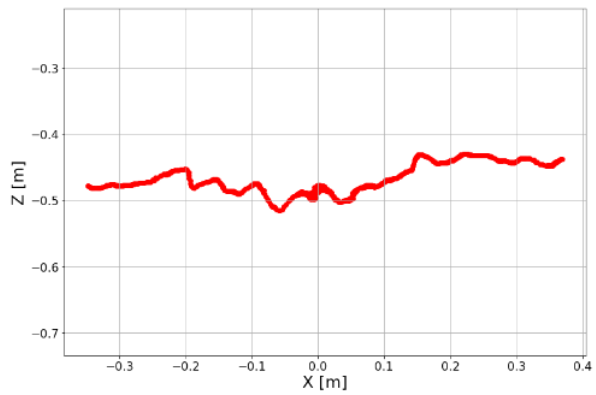

Figure 14

Profiles of 3D plots

The collected 3D images represent numerical characteristics of soil roughness, as well as, sufficient amount of covering plant materials (Fig. 15), which are quite typical for agricultural land, which affects the measurement accuracy. Such tasks as differentiation of soil, plant cover and estimation of the amount of plant material on the field, are objects of interest to soil scientists. With the D435i and integrated high-resolution RGB camera, the color content of the images can be relatively simply used for building the corresponding software.

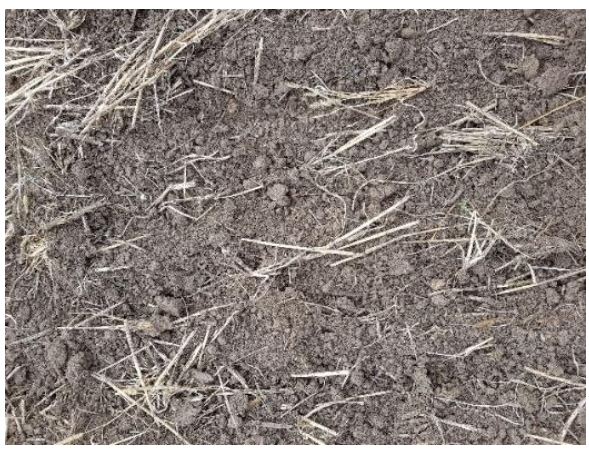

Figure 15

Soil surface coverage with stubble residues 


\section{Conclusions}

In this work, we provide an initial metrological review of D435i camera, as applied to soil science. To this point, we can see certain regular patterns of soil shape and applied tools, but there is scope for the improvement of the methods and results. The RealSence API provides an extensive list of tools and parameters for tuning the D435i camera. These adjustments improve the current accuracy of results. Our aim in the future, in collaboration with soil scientists, is to observe the changes of soil surface roughness in various tillage treatments and climatic conditions, for all seasons. A further scientific interest might be to investigate the possibilities and limitations of the implementation of such a $3 \mathrm{D}$ camera, for movable agriculture machinery.

\section{Acknowledgements}

This research has been partly supported by the FIEK (University-Industry Cooperation Center, FIEK_16-12016-0008) project.

\section{References}

[1] L. M. Thomsen, J. E. M. Baartman, R. J. Barneveld, T. Starkloff, and J. Stolte, "Soil surface roughness: Comparing old and new measuring methods and application in a soil erosion model," SOIL, Vol. 1, No. 1, pp. 399-410, 2015

[2] M. J. M. Romkens and J. Y. Wang, "Effect of Tillage on Surface Roughness.," Trans. Am. Soc. Agric. Eng., Vol. 29, No. 2, pp. 429-433, 1986

[3] J. Vermang, L. D. Norton, C. Huang, W. M. Cornelis, A. M. da Silva, and D. Gabriels, "Characterization of Soil Surface Roughness Effects on Runoff and Soil Erosion Rates under Simulated Rainfall," Soil Sci. Soc. Am. J., Vol. 79, No. 3, pp. 903-916, 2015

[4] L. Li, M. A. Nearing, M. H. Nichols, V. O. Polyakov, C. Larrabee Winter, and M. L. Cavanaugh, "Temporal and spatial evolution of soil surface roughness on stony plots," Soil Tillage Res., Vol. 200, No. March, 2020

[5] K. Herodowicz and J. Piekarczyk, "Effects of soil surface roughness on soil processes and remote sensing data interpretation and its measuring techniques - a review," Polish J. Soil Sci., Vol. 51, No. 2, p. 229, Jan. 2019

[6] R. García Moreno, M. C. Díaz Álvarez, A. M. Tarquis, A. Paz González, and A. Saa Requejo, "Shadow analysis of soil surface roughness compared to the chain set method and direct measurement of micro-relief," Biogeosciences, Vol. 7, No. 8, pp. 2477-2487, 2010

[7] M. Milenkovic, N. Pfeifer, and P. Glira, "Applying terrestrial laser scanning for soil surface roughness assessment," Remote Sens., Vol. 7, No. 2, pp. 2007-2045, 2015

[8] P. Marzahn and R. Ludwig, "On the derivation of soil surface roughness 
from multi parametric PolSAR data and its potential for hydrological modeling," Hydrol. Earth Syst. Sci., Vol. 13, No. 3, pp. 381-394, 2009

[9] U. Wegmüller et al., "Progress in the understanding of narrow directional microwave scattering of agricultural fields," Remote Sens. Environ., 2011

[10] F. Bretar, M. Arab-Sedze, J. Champion, M. Pierrot-Deseilligny, E. Heggy, and S. Jacquemoud, "An advanced photogrammetric method to measure surface roughness: Application to volcanic terrains in the Piton de la Fournaise, Reunion Island," Remote Sens. Environ., Vol. 135, pp. 1-11, 2013

[11] A. Vinci, F. Todisco, R. Brigante, F. Mannocchi, and F. Radicioni, "A smartphone camera for the structure from motion reconstruction for measuring soil surface variations and soil loss due to erosion," Hydrol. Res., Vol. 48, No. 3, pp. 673-685, 2017

[12] J. M. Gilliot, E. Vaudour, and J. Michelin, "Soil surface roughness measurement: A new fully automatic photogrammetric approach applied to agricultural bare fields," Comput. Electron. Agric., Vol. 134, pp. 63-78, Mar. 2017

[13] M. Mirzaei and S. Ruy, "Monitoring of soilroughness caused by rainfall using stereo-photogrammetry," No. January 2012, 2014

[14] H. K. Nishihara, "Practical real-time imaging stereo matcher. Optical engineering, 23(5), p.235536.," Vol. 23, No. 5, 1984

[15] K. D. Mankoff and T. A. Russo, "The Kinect: A low-cost, high-resolution, short-range 3D camera," Earth Surf. Process. Landforms, Vol. 38, No. 9, pp. 926-936, 2013

[16] A. Grunnet-Jepsen, J. N. Sweetser, and J. Woodfill, "Best-Known-Methods for Tuning Intel ${ }^{\circledR}$ RealSense $^{\mathrm{TM}}$ D400 Depth Cameras for Best Performance," Vol. 16, p. 1, 2018

[17] S. Giancola, M. Valenti, and R. Sala, A survey on $3 D$ cameras: Metrological comparison of time-of-flight, structured-light and active stereoscopy technologies. 2018

[18] I. Dekemati, B. Simon, S. Vinogradov, and M. Birkás, "The effects of various tillage treatments on soil physical properties, earthworm abundance and crop yield in Hungary," Soil Tillage Res., Vol. 194, No. July, p. 104334, 2019

[19] I. Dekemati et al., "Long term effects of ploughing and conservation tillage methods on earthworm abundance and crumb ratio," Agronomy, Vol. 10, No. 10,2020

[20] FAO, World reference base for soil resources (2014) International soil classification system for naming soils and creating legends for soil maps. 2014 